(175)

\title{
Comparative Assessment of Trace Element Accumulation in Traditional and Improved Rice (Oryza sativa L.) Varieties Grown with Organic, Chemical and Non-Fertilizers
}

\author{
Rajatheja M.K.J.C. ${ }^{1 *}$, Chandrajith R. ${ }^{2}$, Bentota A. ${ }^{3}$, Jayasinghe G.Y. ${ }^{1}$ \\ ${ }^{I}$ Department of Agricultural Engineering, Faculty of Agriculture, University of Ruhuna, Sri Lanka \\ ${ }^{2}$ Department of Geology, Faculty of Science, University of Peradeniya, Sri Lanka \\ ${ }^{3}$ Rice Research \& Development Institute (RRDI), Sri Lanka \\ *jcrajatheja@gmail.com
}

\begin{abstract}
Oryza sativa L., is the most widely grown rice in Sri Lanka. At present, farmers are using both organic and chemical fertilisers for the paddy cultivation. There is growing concern about heavy metal (mainly $\mathrm{As}, \mathrm{Cd}$ and $\mathrm{Pb}$ ) build up in the soils because they enter the soil and the plants via application of fertilisers (anthropogenic). Heavy metals are also found in the soil (geogenic). Cd and As are both nephrotoxic and neurotoxic, and there is a concern that they may be involved in the chronic kidney disease of uncertain etiology (CKDu) prevalent in the North Central Province and neighboring areas. According to the Food and Agriculture Organization (FAO), the maximum allowable limit (MAL) of $\mathrm{Cd}$ and As is 0.2 $\mu \mathrm{g} \mathrm{g}^{-1}$. This study was conducted to compare the heavy metal accumulation in traditional and improved rice varieties grown with organic fertilisers, chemical fertilisers and without fertilisers. Total of 126 paddy samples (including seven traditional and seven improved rice varieties) grown with organic, chemical and non-fertiliser, were collected directly from the paddy fields in Rice Research and Development Institute (RRDI) at Batalagoda. Soil samples from paddy plots with different fertiliser treatments were collected. Heavy metal analysis was done at the Geology Department of the University of Peradeniya by using ThermoICapQ Inductively Coupled Plasma Mass Spectrometry (ICP-MS). Rice cultivated with chemical fertilisers had the highest mean heavy metal concentrations. Cd concentration $\left(0.32 \mu \mathrm{g} \mathrm{Cd} \mathrm{g}^{-1}\right)$ in traditional varieties grown with chemical fertilisers was significantly higher than in the other treatments. That value is 1.6 fold higher than the MAL. Organic fertiliser treated improved varieties had the lowest level of $\mathrm{Cd}$ and it was less than the MAL. All the other treatments had Cd levels more than the MAL. All treatments had lower content of As than the MAL. Taken as a whole, macro-nutrients ( $\mathrm{K}, \mathrm{Ca}, \mathrm{Mg}$ ) were higher in the chemical fertiliser treated rice than that of organic treated rice. Heavy metals and macro-nutrient concentrations varied from variety to variety.
\end{abstract}

Keywords: Chemical fertiliser, Heavy metals, Improved rice, Organic fertilizer, Traditional rice 